\title{
Estudios
}

\section{NOTAS FILOSÓFICAS PROVISIONALES SOBRE LA ESENCIA DEL CRISTIANISMO}

Fecha de recepción: 05 de febrero de 2021

Fecha de aceptación: 19 de febrero de 2021

RESUMEN: La sustancia del cristianismo está en la idea — por completo deslumbrante y desbaratadora de tantas otras ideas - de que la humanidad y la divinidad se unen; o sea, de que esta humanidad tantas veces diabólica es, sin embargo, capaz de Dios; y lo es no por su condición natural sino por divina condescendencia, aunque suscitando ésta las máximas energías del ser humano. Sólo que estas energías muchas veces deben dedicarse a la destrucción del mal en uno mismo, a una especie de desconstrucción de la figura que se va formando a medida que se vive, más aún que a construir ninguna otra. Sólo la inocencia, sólo una aparente imposible segunda inocencia, una segunda infancia, es la capacidad de Dios.

PALABRAS CLAVE: sagrado y santo; alteridad e intersubjetividad; muerte y experiencia del tiempo; esperanza y amor.

\section{Provisional Philosophical Notes on the Essence of Christianity}

ABSTRACT: The substance of Christianity lies in the idea - utterly dazzling and disruptive of so many other ideas - that humanity and divinity are united; i. e., that this often diabolical humanity is nevertheless capable of God; and it is so

Universidad Pontificia Comillas: mgbaro@comillas.edu;

ORCID: https://orcid.org/0000-0002-4576-435X 
not because of its natural condition but by divine condescension, even though it calls forth the highest energies of the human being. These energies must often be devoted to the destruction of the evil in oneself, to a kind of deconstruction of the figure that is formed as one lives, rather than to the construction of any other. Only innocence, only a seemingly impossible second innocence, a second childhood, is God's capacity.

KEY WORDS: sacred and holy; alterity and intersubjectivity; death and experience of time; hope and love.

\section{UN RELATO EVANGÉLICO}

En general, acepto una de las tesis centrales del espléndido libro de Joseph Klausner sobre Jesús de Nazaret ${ }^{1}$ : que las enseñanzas de éste no añaden novedad a las que circulaban entre los fariseos contemporáneos, de modo que, como vio profundamente Pablo de Tarso, lo capital no es la doctrina en el caso de Jesús sino el mismo acontecimiento que él fue.

Sin embargo, hay factores de las enseñanzas de Jesús que no se acomodan bien con el juicio del sabio historiador judío. Consideremos en este sentido la insondable escena evangélica de Marcos 9,30-37, que empieza mostrando a Jesús que atraviesa rápido la Galilea, rápido y en secreto: hay que instruir a los discípulos por el camino; hay que enseñarles que enseguida se enfrentarán no ya al hecho reiterado de que el profeta sea calumniado, traicionado y muerto, sino a algo mucho más misterioso, dado el secreto que velaba la realidad de este maestro suyo de nueva índole ${ }^{2}$.

El camino, el cielo, los campos, el mar, el ejercicio de viajar a pie eran bien y belleza; pero en las ciudades de los hombres se esconden la fealdad

1 La edición original hebrea se publicó en 1922, en Jerusalén (Yeshua ha-Nozrí). Hay traducción alemana de 1930: Jesus von Nazareth (y una versión española que es traducción de traducción). Klausner añade que la declaración en Jerusalén, en el ámbito del Templo, de que debe darse al César lo que es del César, sí fue algo absolutamente inesperado para los oyentes y el momento en que la adhesión popular cesó y dejó paso libre a la condena del tirano.

2 Es inconcebible que la interpretación cristiana posterior (Dios en carne ejecutado por la justicia humana) no se resienta siempre como una realidad que destroza cualquier interpretación tranquilizadora del mundo histórico. Claro que es el escándalo: un pensamiento que descabala el resto de nuestros pensamientos ordenados, sistemáticos y cada vez más aparentemente llenos de sentido y verdad. 
y el mal. ¡Qué atroz contraste entre la hermosa naturaleza y el horror indecible que se oculta en algunos corazones humanos!

La enseñanza, dice Marcos, contenía también la promesa, la certeza loca de que el condenado se levantaría de la tumba a los tres días de quedar enterrado en ella. Si Jesús llegó a decir tanto, era que evocaba, para él y para todos, la confianza perfecta en Dios Redentor; pero los discípulos, tanto si oyeron la afirmación de esta esperanza como si no, empezaron a meditar cómo defender violentamente al Maestro. O pensaban triunfar de los enemigos o pensaban que la resurrección del Maestro sería, evidentemente, el momento escogido por Dios para terminar con las tiranías, y ellos podrían ser guerreros destacados en el ejército del Bien.

Una vez en la calma de su casa de Cafarnaúm, Jesús se sienta al fin y convoca a las primicias de la nueva humanidad —los Doce- . No necesita que confiesen lo que venían pensando por el camino. Éstos otros seres humanos, que defenderán al Maestro con violencia correspondiente a la violencia de sus asesinos, cavilan encerrados en la historia, en la vida diaria, en la lucha por ganar aquí espacios para el bien, aunque sea con los mismos métodos con los que el mal avanza.

Un hombre conforme al designio de Jesús de Nazaret es, en cambio, el servidor más humilde, y lo es de todos los hombres, de todos esos violentos de causas distintas - de causas no tan distintas, si trabajar por cada una ellas es en esencia lo mismo que trabajar por la otra-. La oposición es realmente o bien estar al servicio o bien dominar; y la palabra servicio se tiene que referir aquí a desarmar las varias violencias, a combatir sin violencia los fines y los medios que los seres humanos proyectamos para hacer nuestra historia.

La persona ha de volverse un niño o, lo que es lo mismo, tiene que dirigirse al niño que ha quedado todavía dentro de los míseros adultos: tiene que tratar con ellos acogiendo a aquel niño que se diría que murió - primera víctima- hace ya mucho.

Jesús abrazó al niño, un niño cualquiera de aquella calle, y lo mostró en el centro de los discípulos, junto a sí. Él es ese niño, y Quien lo envía es también ese niño. Volver a serlo y lograr ver en los demás esto que podrían ellos también volver a ser, es vivir la vida según la concepción de Jesús de Nazaret y del que lo envió. De hecho, nacemos todos en la vida pura y la conservamos mientras no la desfiguramos con las interpretaciones de los adultos, de los hacedores de historia, o sea, mientras no nos hacemos adultos en este sentido nosotros también. 
El niño no tuvo que decir nada: sólo se dejó abrazar y poner en medio. Quizá no sabía aún hablar; quizá Jesús tenía que mantenerlo en pie. Este abrazo silencioso permanece en el fondo del ser de cada uno de nosotros: podemos vivir de su calor eterno.

La sustancia del cristianismo está en la idea - por completo deslumbrante y desbaratadora de tantas otras ideas- de que la humanidad y la divinidad se unen; o sea, de que esta humanidad tantas veces diabólica es, sin embargo, capaz de Dios; y lo es no por su condición natural sino por divina condescendencia, aunque suscitando ésta las máximas energías del ser humano. Sólo que, como enseña el relato de Marcos, estas energías muchas veces, casi siempre, deben dedicarse a la destrucción del mal en uno mismo, a una especie de desconstrucción de la figura que se va formando a medida que se vive, más aún que a construir ninguna otra. Sólo la inocencia, sólo una aparente imposible segunda inocencia, una segunda infancia, es la capacidad de Dios. Y así el conjunto de la historia capital del cristianismo cuenta cómo esta humanidad digna de Dios asesina a la encarnación humana de Dios en medio de una tormenta de mentiras, envidias, crueldades y también aspiraciones que se habrían podido considerar justas y buenas (las que alientan, por ejemplo, en el pueblo de la Alianza contra la abominación del imperio de Roma).

En la perspectiva de la filosofía, el cristianismo propone, pues, una concepción extrema del ser humano, que cubre el arco entero que va desde la inocencia perfecta a la perversidad de un demonio: desde el niño que apenas se sostiene solo y no dice nada que no sea simple verdad, hasta el violador de esa inocencia.

Pero hay un segundo punto poco menos perturbador: la pretensión de que la historia posee de suyo sentido, aunque la trayectoria de su desarrollo vaya desde la oscuridad inmensamente larga de un homínido hasta un horizonte de ultrahumanidad que desconocemos, y se den en ella catástrofes que parecen destruir la noción misma de sentido y apariciones de santidad que se diría que hacen superfluo el resto de ese fluir de milenios y esta cantidad fabulosa de seres personales ${ }^{3}$.

¿Por dónde y cómo afrontar filosóficamente estos inmensos problemas de la esencia del cristianismo? Este ensayo sólo podrá, como es evidente,

\footnotetext{
3 Espléndidas variaciones sobre ambos puntos clave se encuentran en S. Kierkegaard, respectivamente, sobre todo, en El concepto de ansia y en Postscriptum no científico a las Migajas de filosofía.
} 
señalar algunos pasos dentro de esta cuestión — que es de la mayor importancia para quien lo escribe-.

Un acceso que se viene practicando respecto de todas las preguntas suscitadas en la filosofía de la religión, al menos desde el auge del interés por las ciencias históricas al derrumbarse la columna vertebral del sistema hegeliano pero persistir sus secuelas en la ciencia empírica, es iniciar el tratamiento de la cuestión en la fenomenología de la religión.

Esta disciplina es quizá el caso mejor logrado (y casi único) de interdisciplinariedad extendida a la historia, la antropología cultural, la filología, la teología, la filosofía y variados aspectos de las ciencias, incluso, de la naturaleza. Uno de sus frutos de madurez ha sido, precisamente, reconocer que la palabra religión es un formidable ejemplo de uso analógico de un término; lo que implica que casi haya que hablar más de fenomenología de las religiones, en plural, y abandonar el singular ${ }^{4}$.

Esta evolución viene afortunadamente al encuentro de algunos de los planteamientos más interesantes, más profundos, de la metafísica contemporánea. Nos permite no tener que realizar una crítica radical de la fenomenología de las religiones, aunque también es verdad que en parte nos exime de la necesidad de partir de ella a la hora de considerar un problema como el que es objeto de este ensayo.

Resulta evidente que no podré analizar posiciones de la filosofía primera reciente que tengan algo menos que ver con la esencia del cristianismo. Tendría que escribir un libro enorme, y puede que empleara no de la mejor forma posible así mi tiempo. El camino que parece ofrecerse como el adecuado pasa, en cambio, por dejar al margen grandes fenómenos culturales - entre los cuales el más difícil de evitar seguramente es el llamado segundo Heidegger- y concentrar la atención, al comenzar, en dos tesis próximas entre sí, ambas llenas de lo que entiendo por sentido religioso, ninguna de las cuales se pretende cristiana. Sin ellas puede que sea aún más fácil errar demasiado en un problema de tantos aspectos y tan gran dificultad.

Me refiero a la necesidad de diferenciar sagrado y santo y a la pretensión elevada contra la ontoteología por el nuevo pensamiento.

4 Insistió en ello las últimas décadas de su vida Juan Martín Velasco en innumerables ocasiones y en la versión última de su Introducción a la fenomenología de la religión. 


\section{SAGRADO Y SANTO. RUPTURA DE LA TOTALIDAD}

El hecho de que no sea una distinción ni clásica ni siquiera antigua no merma en absoluto el interés que tiene la propuesta de Emmanuel Levinas en el sentido de que separemos tajantemente lo sagrado de lo santo ${ }^{5}$. Desde luego, si seguimos esta idea, partimos en dos, por lo menos, la fenomenología de lo religioso y lanzamos al ámbito de lo mítico, lo afectivo, lo natural, lo idolátrico a un gran número de fenómenos que desde hace unos doscientos años al menos denominamos religiosos. Incluso, si nos atenemos al contenido completo de lo que ha defendido Levinas, prácticamente todas las formas conocidas de la mística pasarían del lado del culto de lo sagrado, tal como se las interpreta con frecuencia y hasta tal como las han solido describir quienes las han vivido. Sólo una forma muy determinada de monoteísmo sería, en definitiva, culto de lo santo, y abarcaría el judaísmo rabínico, quizá el islam sunní de las escuelas jurídicas más antiguas y, atenuadamente y con mezclas, el cristianismo, en especial, el protestante - aunque algo esencial en el propio cristianismo ha de recibir la crítica de ser un residuo pagano- Sin embargo, el mero anuncio de que así queden las cosas no debe apartarnos de considerar con atención la doctrina del sabio judío, en la medida en que, a diferencia de él, nosotros experimentemos el cristianismo como una manera de judaísmo - evidentemente fue así siempre, pero ante todo en Jesús de Nazaret y la generación apostólica, incluido Pablo—. Lo que importa es qué se puede aprender de la confrontación con Levinas. Tras de la cual, por cierto, una noción depurada de mística ha de aparecer y mostrarse en plena correspondencia con la experiencia de los cristianos que más intensamente han vivido su relación con Dios.

Es interesante observar que Levinas no cita, en el contexto al que me estoy refiriendo, a un autor al que sin duda conocería, pero al que unánimemente (y, a mi juicio, cometiendo un grave error) se ha postergado: Karl Jaspers; y, sin embargo, apenas treinta años antes de la publicación de Totalidad e infinito, este gran pensador alemán, en la primera edición

\footnotetext{
5 Además de ser el título mismo de una de sus obras de comentarios talmúdicos, se afronta directamente este asunto ya en Totalidad e infinito y aún más en De otro modo que ser o más allá de la esencia.
} 
de su monumental Filosofía ${ }^{6}$, clasifica a todas las formas de la religión tradicional o histórica como cesiones a lo mitológico, o sea, como perversiones de lo realmente metafísico.

Como ya había sucedido en la época del idealismo clásico en Alemania, Jaspers sólo admitiría que, por analogía, casi equívocamente, se llame religión al ejercicio estricto de la filosofía — que culmina con la difícil relación inobjetiva con la Transcendencia: con lo totalmente otro, si queremos ofrecer una mínima descripción desde muy lejos de en qué consista la Transcendencia-. En Jaspers todo indica que se trata, en perspectiva subjetiva, de una hipérbole del protestantismo; en Levinas, en cambio, las hipérboles resultan por completo insuficientes, aunque se las usa muchísimo, para reflejar en proposiciones (en el material de lo Dicho) la radical pureza de la óptica del monoteísmo (judío de tradición fariseo-rabínica).

Es evidente que, tanto en el caso de Levinas como en el de Jaspers, a la defensa de que hay de alguna manera, de otro modo que siendo, la transcendencia, se aúna la exigencia de que es preciso vivirla (no sólo pensarla y estimarla) lo más alejada posible de lo humano y de lo mundanal. Como proponía en las bases de su trabajo Franz Rosenzweig, ser humano, mundo y Dios, aunque ahora se muestren conjuntados, ni ahora ni nunca se reducen uno a otro. Su reunión no es un sistema dialéctico en que las tres esencias terminan por ser una única; es, en cambio, precisa y justamente, un estar vinculados como por, tan solo, la conjunción copulativa (aunque de este vínculo respetuoso con las diversas índoles de lo unido se deriven luego relaciones especiales, materiales, por así decir, derivadas de cómo son de suyo el mundo, el hombre y Dios). El precepto filosófica y religiosamente fundamental, no tomar en vano el nombre de Dios (ni el nombre del mundo, ni el nombre del ser humano), se expresa ante todo en este movimiento de separación en que se origina lo que Rosenzweig denominaba nuevo pensamiento ${ }^{7}$. Porque es verdad que la tradición clásica de la ontología occidental, al menos desde Aristóteles hasta Leibniz y Hegel, no vio así el conjunto de los temas de la metafísica, sino en la perspectiva opuesta, que ya Kant llamó - para repudiarla-ontoteología ${ }^{8}$.

6 Apareció en 1932 y significa en muchos sentidos una recepción sumamente crítica del libro de Heidegger de 1927, Ser y tiempo.

7 Así ya desde el comienzo mismo de La estrella de la redención (1921).

8 Lo más esencial sobre ello lo aporta la llamada Religionsphilosophie Pölitz (volumen XXVIII, 5 de la edición académica). Los cuadernos — no suyos propios- que editó Pölitz aparecieron en 1817. Naturalmente, la ontoteología (cuya esencia es el 
El nuevo pensamiento ancla en la ruptura de la totalidad, o sea, en el reconocimiento, tras dos mil años de ceguera mayoritaria, de que no hay originariamente tal totalidad, pero la filosofía ha caído y creído en ella en su forma vieja.

Por cierto, en la obra de Jaspers mundo, existencia y transcendencia se corresponden con las ideas conforme a la sistemática de la Crítica de la razón pura, pero también con los tres temas clásicos de la ontoteología, ahora igualmente rotos, estallados ante el filósofo y ante el ser humano libre que se relaciona existencialmente con la transcendencia.

La cuestión de la fragmentación de la totalidad no es en absoluto un tema abstruso de la especulación. En primer lugar, no lo es sencillamente porque se nace, aunque ignorándola, de algún modo en la verdad, y la totalidad es la antiverdad; pero, en segundo lugar, por motivos existenciales de máxima relevancia. Uno al que acude Rosenzweig es que la filosofía habría cerrado con Hegel su ideal fundacional y habría así dejado a la vista de todos que el problema candente por el que comenzó está del todo abierto y tan ardiendo como si no hubiera habido el esfuerzo de dos mil años de ontoteología; y este problema es universal y cotidiano: el del sentido de la vida humana abocada a la muerte.

En realidad, el otro motivo gravísimo que denuncia como fantasma ilusorio pero muy peligroso a la totalidad es la certeza ética, más allá y más acá de la presunta evidencia que la combate desde la ontología, la vieja pero tan frecuentada ontología. Rosenzweig la encuentra en Kierkegaard, en Schopenhauer, en Nietzsche; pero se revela con fuerza extraordinaria en la catástrofe de la Gran Guerra - y debería haberla rastreado el pensador en Sócrates, en Cristo, en la historia martirial entera de los santos asesinados y calumniados-. Levinas y los testigos de la Catástrofe por antonomasia, la Segunda Guerra Mundial con la Shoá en su centro y el Gulag y las revoluciones culturales de Extremo Oriente y la explotación esclavista del Sur en sus secuelas, han podido sentirla y describirla con una rotundidad que ya no podrá ser sobrepasada.

Esta elocuente descripción se encontrará sobre todo en las primeras páginas de Totalidad e Infinito. La hipérbole metódica se refiere aquí a la experiencia misma de lo que auténticamente es real: aquello tan duro que

tratamiento de «Dios» como un objeto más) revive constantemente hasta ahora mismo, cuando, en cambio, el platonismo original no participa de tal cosa, según la interpretación de él que cada vez voy ahondando más. 
destroza no sólo las ilusiones sino el carácter moral de un ser humano (que así se revela como la principal de las ilusiones). Cabe que, mientras no surge el caso serio, nos creamos buenos y situados en el puesto de la vida que nos ha adjudicado la divinidad misma. Giges encuentra el anillo que lo vuelve, casi a la vez que invisible, un monstruo moral: las raíces de su persona no estaban cultivadas por el bien, sino por el miedo a ser descubierto; ahora que está seguro de no serlo, no es capaz de evitar que su verdadera naturaleza aflore, y ésta entonces estalla en un sinfín de egoísmos que no se detienen ante los peores crímenes.

Pero puede ocurrir algo más terrible: que nos hayamos protegido de la misma idea del anillo de la invisibilidad y seamos unos ciudadanos correctos, ejemplares, encajados en nuestro positivo papel social. Sobreviene de repente una catástrofe, aparece un tirano, se requiere de las personas honradas y cabales la colaboración servil con los fines de la dictadura, y nosotros, miembros destacados de nuestra sociedad, nos ponemos como naturalmente a obedecer en lo importante aunque quizá resistamos un poco en lo accidental y en las formas. La violencia de la realidad puede arrasar nuestra tranquilidad moral. Y si lo que ocurre es que se desencadena una monstruosa persecución irracional contra la gente a la que pertenecemos, aún será más fácil sentir que la violencia es incontrastable. Se nos moviliza, se nos arranca de nuestra morada existencial cotidiana: lo que nos parecía definitivo y estable y nos daba seguridad y paz, se deshace y hemos de adoptar un cierto personaje nuevo. La catástrofe se habrá consumado cuando nos veamos realizando actos que enseguida comprendemos que harán en el futuro imposible todo otro acto responsablemente nuestro. Todavía vivos, habremos muerto tanto para la vida verdadera como para la muerte consoladora. Sin apenas haber tenido ocasión de resistir, habremos sido llevados a la desesperación porque se han combinado la violencia externa y la vaciedad interna de nuestro personaje.

Si exageramos lo que sucede en una circunstancia así, diremos posiblemente que el ser, lo real, se ha impuesto pronto al bien, a lo ideal, a lo que no hay y no es, pero debiera ser. La libertad no nos ha servido más que para rendirnos, humillarnos y lograr la desesperación.

Desde el punto de vista intelectual, lo que se manifiesta aquí es que, para quien desespera, la verdad era y sigue siendo una cierta totalidad de la que él se sabe tan sólo una parte; y la parte aislada no sólo no se enfrenta con el todo dentro del cual está, sino que siempre, haga lo que 
haga, colabora al desarrollo de él. La ilusión de poderosa libertad individual, al quedar atrapada en nuestra visión de la realidad como un todo único, se desvanece: no somos ontológicamente más que portadores de algún ramalazo de las energías de la Totalidad. Está entonces justificada nuestra radical deserción de lo que en realidad sólo habíamos soñado que era definitivamente nuestra identidad moral, nuestra vocación capital y nuestro refugio; y la única receta que se nos ofrece contra la desesperación consiste, justamente, en comprender que no podíamos otra cosa porque no éramos otra cosa. El ser se manifiesta en violencia primero y horrible acogida después: nos deshace para recibirnos. El significado de todas las cosas y todas las vidas está en la consumación a la que alguna vez llegue el Todo. Podemos llamarlo naturaleza, pero también, y con consecuencias mucho más potentes, historia. ¿Es que nos creíamos distintos de la naturaleza e independientes de la historia? La verdad es que somos parte de la primera y absolutamente parte de la segunda, ya que la misma naturaleza es únicamente un soporte del Todo absoluto: la Historia. Su arco evolutivo misterioso e inmenso es lo que al final adoran todos los seres humanos: es la divinidad misma y lo único realmente real.

La definición de lo religioso en el hombre la dio, en este sentido, el romanticismo, a la vez que brindaba por el espíritu de Espinosa: se trata del sentimiento de dependencia absoluta, que ha de haber sido el afecto primero y fundamental de la humanidad desde su nacimiento. Los Discursos sobre la religión, de Schleiermacher, presentan esta idea, esta Totalidad, con una elocuencia que probablemente no se ha superado nunca, aunque la frase misma sobre el sentimiento de dependencia radical pertenezca a otro texto posterior de la pluma del pensador. ¿Qué es nacer sino brotar en el seno infinitamente fecundo y pródigo del Uno y Todo, de la Realidad Total y Absoluta, que está en perpetua marcha hacia la expresión definitiva de lo que ella es? La realidad nos acoge en el mismo instante en que nos envía el don de dones de nacer. La raíz de nuestra existencia, antes de conocer y antes de actuar, no puede consistir en otra cosa que en el oscuro afecto de la humildad absoluta: Todo, esto Infinito que nos ha hecho y nos mantiene, es lo Único y, por ello mismo, lo Bueno y lo Bello, lo Verdadero y lo Dotado de pleno sentido. La sabiduría de la primera infancia está en sentir aún que el cordón umbilical con el Uno y Todo no se ha cortado. Más adelante, la necesidad de saber y hacer va difuminando la presencia constante de la Totalidad y nos induce a concepciones de lo real que van incurriendo en una serie de falsedades por 
falta de completud. Y si se nos devuelve a la verdad del Uno y Todo, será precisamente porque descubramos que cuanto sucede debería recibir el nombre que jamás le damos: milagro. Nada real está desprendido del sentido sobreabundante del Uno y Todo, dentro del cual yo y todos nos movemos y existimos. Sea cual sea el acontecimiento que nos retrotrae a la verdad, debemos acogerlo con máxima gratitud, incluso si moralmente nos merece a primera vista la calificación de crimen monstruoso.

Levinas ha combinado en cierto modo esta visión romántica (y realmente monstruosa) de las bases de lo antropológico tanto con la historia empírica del hombre como con la fenomenología de lo elemental. Estar vivo es estar viviendo de los recursos abiertos, inmediatos, fáciles, paradisíacos de este mundo: el aire, la tierra, el agua, el fuego de la luz y de los alimentos, la compañía de los demás. La base de la existencia humana es el gozo de este paraíso en que nacemos, y disfrutar de los bienes elementales de él es el modo en que se cierra dentro de lo real el bucle de un yo; pues, en efecto, vivir de los elementos disfrutándolos es gozar del goce de ser a la manera humana: un rudimento de ipseidad o mismidad, una primitiva autoconciencia, el despertar de un psiquismo. Pero ha señalado inmediatamente Levinas, ya ahí, el lugar en el que se origina el contacto con lo numinoso. No es la fiesta del disfrute del mundo, sino la inquietud de que nuestro sustento desaparezca. Hay en los elementos una oscura profundidad que no se puede sondear pero que, en cuanto se la vislumbra, amenaza con que la presencia del alimento necesario pueda interrumpirse y quizá no volver nunca. El disfrute se interpreta entonces como integración y participación (la palabra que usaba Lévy-Bruhl al tratar de captar lo que llamaba el alma primitiva) en el ser mismo de lo que nos alimenta, y el culto es ansia de hacer inacabable la rica presencia de esto divino e inmediatamente dado, gracias a lo cual vivimos y nos volvemos yoes. Los factores elementales de la vida, los alimentos terrenales esenciales cobran la figura de los númenes: la pura cualidad en que consisten y que no vemos de dónde surge, se vuelve sustancia con nombre propio, que garantice que seguirá habiendo de ella incluso cuando nos falte. La necesaria personificación de los elementos es, por supuesto, imprescindible para que tengan oídos, ojos y narices que sientan la intensidad devota de nuestros cultos. Comulgamos con la esencia de los dioses y así formamos una comunidad de mística participación entre todos nosotros y los mismos dioses; una comunicación que se pueda mantener en 
la ausencia, en la terrible misteriosa distancia a la que a veces se aparta lo que más necesitamos, aquello de lo que dependemos absolutamente.

Tal es lo sagrado ${ }^{9}$. A medida que los aspectos de la existencia se diversifican y se ahondan, y van así surgiendo nuevos goces y nuevas revelaciones de los elementos, adopta lo sagrado formas nuevas de su tremenda fascinación mayestática. Claro que tienen realidad estas divinidades, pero justamente como los factores que se tienden hacia la vida humana desde el seno inmenso y desconocido de la Totalidad. Sus cultores han de proveerlos luego de caracteres que de suyo no tienen, pero que son necesarios para la plenitud de la liturgia ${ }^{10}$.

Totalidad, amenaza, participación y sociedad son, entonces, los componentes principales de la vivencia de lo sagrado como, en general, sentimiento de dependencia incondicional.

Desde el punto de vista histórico, como sobre todo supo entenderlo el Schelling maduro, la mitología es la fase incoativa pero imprescindible de la revelación. En otras palabras, el politeísmo es necesariamente anterior al monoteísmo.

Pero quizá no sea así, como antes insinué, en perspectiva individual, puesto que, antes de toda comprensión activa de las cosas, un ser humano es implantado por su nacimiento en la verdad, y no ha de ser absolutamente imposible que, por fuerte que sea la corriente de la tradición en que se le eduque, él logre reavivar en su propia vida de individuo la verdad primigenia que a todos se nos concede.

Es claro que semejante verdad de la que no hay conciencia, que no se puede asumir, para cuya experiencia ya siempre habrá que utilizar los recursos de la lengua materna y de la tradición familiar, no tiene, por su parte, que ser la verdad entera, sino sólo su germen o su promesa. Tiene que consistir en una verdad que tienda a ser desarrollada o que se pueda ver cumplida como se cumple una promesa: andando el tiempo y colaborando el individuo con la realidad exterior, que tendrá que ir conociendo cada vez más matizadamente a medida que vive. En términos religiosos,

9 Convendría para todo ello leer primero las partes A, B y C de la sección II de Totalidad e Infinito (titulada Interioridad y economía) y regresar luego al § 6 (Lo metafísico y lo humano) de la parte B de la sección I (Mismo y Otro).

10 Cfr. el excelente ensayo de Jean-Yves Lacoste L'intuition sacrementelle, en la Revue théologique de Louvain 42 (2011), 496-525. Aquí Lacoste, en referencia explícita pero brevísima a Levinas, discute la diferencia entre sagrado y santo confrontándose con el pensamiento último de Heidegger. 
se puede decir que no hay religión natural alguna, al mismo tiempo que cabe defender que se nace en y a la verdad plena (en cuyo ámbito no puede faltar lo que sea la verdad religiosa).

Hay al menos un caso en el paganismo antecedente de nuestra concepción del mundo en que se muestra con maravillosa claridad cómo cabe realizar en la madurez de la existencia la ruptura de la Totalidad, o sea, cómo cabe experimentar que tal es desde siempre la verdad. Se trata del caso Sócrates, al menos en el dibujo que trazó de él Platón. En este ejemplo se ve cómo el sentimiento de honda relación con lo divino se traduce en otro de perfecta libertad respecto del mundo, tanto natural como histórico. La compenetración con lo Bueno mismo y puro, que puede ser experimentada como un éxtasis, como un salir momentáneamente el ser humano de su propia condición llevado por la conjunción del amor eros y el amor agape, es socialmente, en sentido literal, filantropía exenta de toda contaminación mítica y es además dominio sobre la naturaleza. Cabe enfrentarse a la violencia de la realidad natural y a la mucho más grave violencia extrema de la sociedad justo por amor a la belleza de aquélla y a las posibilidades de ésta, sintiéndose a la vez muy cerca de la acogida en lo divino. Un individuo puede controlar el miedo de su cuerpo a la muerte biológica y de su alma a la muerte social tras haber superado la violencia de lo sagrado. Con todo lo que parece real, con la Totalidad en contra, la razón, o sea, una conexión primordial con lo Real refrendada por la madurez de la existencia, logra que un ser humano inmensamente lúcido adquiera la extraordinaria valentía que le obliga a salvarse en medio de lo que cualquier otro tomaría por su destrucción, aplastado por todas esas fuerzas incontrastables.

Sócrates interpretó su existencia como el haber sido colocado por Dios en un puesto avanzado en la batalla de la vida ${ }^{11}$. Sólo se trata de no abandonarlo, pase lo que pase en torno. La lucidez nos ata con una verdad, la del Bien, más real que la Totalidad, o con un modo del ser que es más que el resto de seres. Y ese ser, el Bien puro, jamás amenaza, jamás causa males, sino que vincularse a él (promesa de nacimiento realizada por la valentía razonable del combate en la vida) termina por volver

11 Platón, Fedón, 62 b. Me permito remitir a mi comentario (con traducción) del decisivo diálogo platónico Gorgias (Salamanca, 2010), que subtitulé: La paz es la búsqueda de la verdad. 
invulnerable al ser humano, o sea, por ponerlo a salvo de todo atentado que contra él procuran las demás realidades.

Esta combinación extraordinaria (pero que debería ser ordinaria y universal) de valentía, razón, sentido de la realidad y amor del bien (que implica amor a las pobres cosas y las pobres personas que nos atacan) es una posibilidad de la que disponemos siempre todos. Jaspers, justo por esto, no dice que existamos ante la transcendencia como si tal fuera nuestra naturaleza, sino que ex sistir (que se aproxima a lo que llamaba yo antes ék-stasis) es una posibilidad del ser humano. Nuestra alma puede ex sistir si salta libre, lúcida y valientemente por encima de la acometida de la violencia de la naturaleza, los hombres y los dioses míticos. En nuestra época, esta violencia suele ejercerse como ingeniería social, o sea, como una técnica que se extrae subrepticia y perversamente de la ciencia interpretada como verdad de la Totalidad incoercible. Y ésta es una interpretación, a su vez, perversa, cobarde e irracional ${ }^{12}$.

Sentirse y saberse valientemente unido a la transcendencia como misterio de bondad insondable es aquello a lo que yo llamaré mística o culminación simultánea tanto de la búsqueda filosófica como de la auténtica religión. Esta unión que hay que confirmar día a día, instante por instante, lo hace todo nuevo y todo posible en formas innumerables y de belleza indescribible, cuando es, al mismo tiempo, solidaridad muy honda con el resto de lo real de lo que, precisamente, se siente entonces el individuo desapegado, absuelto y libre. El sentimiento de libertad radical respecto de la naturaleza y de la historia es sentimiento de unidad (pero de diferencia también y, por ello, de incondicional sumisión) con el bien perfecto, fondo del ser y de todos los seres; y es también sentimiento de amor a todas las personas y todas las cosas (tanto más amor cuanto mayor sea la libertad a su respecto).

Sólo si el cristianismo queda así pálidamente descrito puede ser verdadero, porque en realidad, si lo es, como revelación misteriosa de lo divino, como cumplimiento de la promesa originaria, tiene que desbordar la elocuencia y la capacidad experiencial de cualquier ser humano.

12 Tal es el sentido último de toda la primera sección, Weltorientierung, de la Filosofía de Jaspers. Creo imposible exagerar la importancia crucial de esta visión de las cosas. 


\section{MONOTEÍSMO}

Un reciente ensayo de reducir la vertiginosa paradoja cristiana y continuar, gracias a ello, hablando de una acción humana que abriría la dimensión religiosa general, universal, es el análisis de la oración que expuso en 1998 Jean-Louis Chrétien y que, en la intención de su autor, recoge incluso los momentos de casi religión de una existencia atea (puesto que también quien se afirma ajeno a toda religión y a toda Iglesia puede dirigir la palabra a alguien que en realidad supone que no existe).

Puede sorprender que el primer rasgo de esta honda descripción fenomenológica consiste en hacer de la oración, sin embargo, una antropofanía, cuando alcanza la plenitud: una exposición de todo el ser humano, que comprende todos los aspectos de éste. Ahora bien, es que semejante radical y completa autoexposición jamás tiene lugar ante un espejo ni es asunto al alcance de Narciso. Muy de acuerdo con Levinas, a quien no cita, Chrétien mantiene que hablar es ya estar siendo enseñado, mucho más que enseñar. Si nos olvidamos de las palabras reales de la lengua en que se formula la oración que ni sale de los labios, dejaremos fuera de la autoexposición un factor capital de la humanidad.

No se habla más que ante una mirada posible, ante unos ojos aunque se encuentren en lo invisible; pero, sobre todo, hablamos respondiendo, no iniciando en nosotros solos la serie de las palabras. De este modo, más que recibir noticias de sus propias palabras, es el hecho de hablar el que enseña al hablante. Algo así como un giro alrededor de sí mismo, para cerciorarse de que todo él se halla presente y abierto, es lo que se produce, afirmo yo, al hablar calladamente en la dirección de lo absoluto. Es la invisible casi presencia de éste la luz misteriosa que da a conocer al sujeto orante a sí mismo. Chrétien la compara con el origen del que viene el aire que uno absorbe en la respiración.

Pero la pieza clave que apenas se insinúa en este tratamiento del fenómeno que habría de ser el fundamental dentro de los fenómenos religiosos, es que no podría nadie ser capaz de hablar en la dirección de lo absoluto invisible si antes no se hubiera enfrentado a tener que responder a un hablante humano ${ }^{13}$. Quizá en el desamparo de no poder trabar con

13 No puedo estar de acuerdo con que no haya prolegómenos ni nada previo a la oración, como sostiene Chrétien en la p. 34 de su ensayo La parole blessée. Es a este texto al que hago continua referencia en el mío. Se lo encuentra recogido, como 
ninguna persona una relación de verdadera intensidad o suficientemente sincera, habla uno a lo invisible y supremo; pero nunca empieza por recibir de éste la inspiración primera, igual que el aire del que goza el pulmón sólo muy lejanamente es de alguna manera aliento del Creador. Incluso parece que se puede decir que la oración tiene que comportar un elemento de desdicha o de culpa, de fracaso o de límite, que justamente no tiene por qué entrar en el complejo de todo diálogo interhumano. Cuando Levinas se atreve a decir que hablar siempre tiene un prólogo de apología o defensa de uno mismo, no lo hace pensando en el disparate de que siempre quien habla deba sentir su miseria ante el interlocutor, o callaría y pasaría de largo. Lo que Levinas implica es, más bien, que la conversación entre los seres humanos tiene esencialmente el sentido inverso: al hablar yo respondiendo al otro próximo, dejo a un lado mi culpa y estoy ya sirviéndolo, cuidándolo, dándole riquezas que ignoraba yo tener. El otro próximo me enseña la imperiosa necesidad de cuidarlo, de respetarlo, pero empezando por ofrecerle el mundo mismo que compartimos, sólo que traducido en descripciones, en juicios, en significados. Que yo esté como por debajo, al servicio del otro, expresa más bien mi capacidad de darle las cosas, de acercarle el mundo y los recursos de él que precisa para vivir. Es hacerle justicia y rendirle homenaje y, si se quiere utilizar la hipérbole, es también en cierto modo darle culto, porque su presencia delante de mí es ya la orden de considerarlo santo, separado, absuelto de mí mismo y como constituyendo la revelación del mandamiento no dañarás, no asesinarás, no mentirás, no envidiarás.

Nada de todo ello tiene sentido en la oración, más allá del diálogo. A lo absoluto no cabe darle más que la propia presencia integral, pero no el pan y la sal, el agua y el aire de este mundo, y ni siquiera nuestra amistad. Sólo podemos afrontarlo si antes hemos hablado de veras con nuestros próximos y de alguna manera no hemos logrado ser suficientemente directos, claros, observantes de su dignidad y de sus necesidades. Como apunta agudamente Chrétien, sólo entra en la oración el que se sabe indigno de ella, pero esta sabiduría sobre sí mismo no la alcanza más que cuando entra en la oración. La causa está en la opacidad con que conocemos nuestra condición lamentable cuando sólo recibimos noticias

capítulo segundo, en L'arche de la parole (París, 1998). En cualquier caso, la obra de Chrétien merece una recensión completa, y, en lo que hace al tema de este ensayo, esa recensión debe partir de un análisis cuidadoso de Lueur du secret (1985). 
de nosotros mismos en el trato con los humanos próximos. Nuestras injusticias y nuestra incomparecencia enseguida imaginamos que se compensan o entran en relación compleja con las que los demás practican contra nosotros, y en esta red de comparaciones vemos más cómo son los demás que cómo somos nosotros. Pero una inquietud oscura empieza a trabajarnos y no logramos evitarla por más sacrificadamente que sirvamos a quienes tenemos cerca. Tal inquietud nos lanza al desierto de Dios, al monte donde quizá encontremos la zarza que el fuego no consume y el acontecimiento no interhumano del perfecto descubrirnos al desnudarnos hablando a lo Invisible absoluto.

Hay que haber hecho muchas obras de amor, muchos trabajos imperfectos de amor y justicia que quizá se pierdan sin encontrar a quien debían servir, para que se acendre realmente la posibilidad, la necesidad, la realidad al fin de una auténtica oración ${ }^{14}$.

De aquí que entre las aportaciones más valiosas de la filosofía actual a la filosofía del cristianismo se encuentren, sin duda, los análisis acerca de la intersubjetividad y la proximidad tanto de Levinas como de Henry, complementados por las tesis antropológicas de Maldiney, de Romano, de Lacoste... ${ }^{15}$.

Levinas ha podido escribir, con razón sobrada, que los fenómenos que seguimos llamando religiosos en los que la relación interpersonal no es la etapa fundamental, la religión misma, como él afirma atrevidamente, pertenecen por completo al pasado y manifiestan haberse quedado en lo sagrado y no haber trascendido jamás hasta lo santo ${ }^{16}$. Acabamos, por nuestra parte, de ver uno de los aspectos más claros de por qué es así.

Pero Levinas prolonga su meditación en una crítica radical de esa condición de la existencia a la que llamó Heidegger ser-con. Para el maestro de Levinas, el horizonte de los otros existentes al modo en que yo mismo existo se abre por mor de mí mismo y como un lado de la faena de ser que

14 Parte fundamental de mi trabajo desde hace veinte años está dedicada a esa fenomenología narrativa, que dejo aquí al margen.

15 En el caso de Michel Henry, hay sobre todo que recurrir a Phénoménologie matérielle (París, 1990) y a Incarnation, une philosophie de la chair (París, 2000); en el de Henri Maldiney, a Penser l'homme et la folie (Ginebra, 2007); en el de Claude Romano, a L'événement et le monde (París, 1999); en el de Jean-Yves Lacoste, a Expérience et absolu (París, 1994). (Hay traducción, o la habrá pronto, de todos estos libros capitales en la Colección Hermeneia, de Ediciones Sígueme.)

16 Totalidad e Infinito, p. 83 de mi traducción. 
es siempre la mía. No sólo esto: en la esfera primordial de este trabajo lo que se encuentra es mi estar desde siempre afrontando los entes intramundanos como seres a mano, como utensilios que remiten unos a otros precisamente en el contexto de mi cuidarme de mí mismo ocupándome laboriosamente con lo cercano no personal, no existente. Sólo que mi labor cotidiana está sugerida, ordenada o aprovechada en maneras diferentes por los demás, que así comparecen también, a modo de apéndices de mis obras ${ }^{17}$ — quizá innecesarios en una situación robinsonesca como la que dibujó en el medievo Ibn Tufail para su Viviente, hijo del Despierto-.

En absoluto sucede así, sino que el estar alterado por el otro y por Otro es el fundamento inmemorial de mi mismidad, de mí mismo, del yo. No se trata tanto de una situación crucial o límite (o sea, constante, como es el sentido original en Jaspers de tales situaciones) en perspectiva ontológica (aunque también lo es), cuanto de una determinación que se capta primero con la mirada de la ética. No deriva, pues, sencillamente de la condición desvalida de quien nace y de la necesidad empírica de ser recogido para empezar la faena de sobrevivir. Es más bien, por difícil que sea el intento de describir tal cosa, que el sentido, la orientación sin la cual no cabe vivir hacia algo o alguien, no está autocentrado, no tiene en mí y en mis actos intencionales su arranque.

Toda vivencia intencional mía, así como el gozo de los elementos del mundo, la alimentación gracias a la cual vivo, están sostenidas por la exterioridad. Vivo del aire, del agua, de la tierra; pero a este movimiento que ya quedó descrito como constituyendo un bucle de egoísmo inicial que parte, sin embargo, de algo otro exterior, siguen las articulaciones existenciales del cuerpo, del habla, de la morada: tengo y ocupo espacio porque tengo tiempo que me distancia de las cosas que cumplirán mis necesidades (y cabrá decir que esta realización característica, adverbial, de la existencia, en que se anudan necesidad, satisfacción, paraíso, distancia y tiempo, es la noción misma de cuerpo).

Pero, ¿qué es en definitiva tener tiempo? ¿Qué o quién me regala no ya el aire que respiro sino incluso el tiempo de respirar o de contener el aliento? Sin esta diacronía entre las cosas y yo no habría posibilidad alguna de existir ni, desde luego, acto alguno de conciencia. No habría representaciones, cuando tan gran parte de la historia del pensamiento

17 Resumo así apretadamente las tesis de los primeros capítulos de Sein und Zeit (1927). 
ha hecho de la representación (sensible, intelectual o propia de la llamada inteligencia sintiente) el piso sobre el que se sostiene toda otra intencionalidad.

Me permito reescribir aquí los laconismos de Levinas según ellos me alumbran estos espectáculos que me retrotraen en cierto modo a más atrás y más adentro que yo mismo.

Levinas afirma que la libertad de la donación de sentido en la representación (y en los actos no objetivadores que se montan luego sobre las representaciones) es algo de lo que somos investidos, no una dote propia e innata. Es una libertad bajo crítica ya siempre, es decir, que sabe de alguna manera que tiene, por ejemplo, la responsabilidad de constituir las cosas del mundo tal como son, y no arbitrariamente y tal como nos placería que fueran.

Semejante crítica previa ya al ejercicio de la donación de sentido y de todo acto libre podría achacarse al maestro interior, pero ya ello indica, desde luego, a un maestro de índole parecida a la mía pero que no soy yo mismo. A un yo más yo que yo mismo o, como prefiere Levinas, al otro prójimo primordial, que no puedo, por supuesto, localizar empíricamente. $\mathrm{Y}$, sin embargo, no es algo así como un a priori vago, neutro, porque precisamente critica, habla, me fuerza a la responsabilidad. Tampoco necesito pensarlo como siendo Dios, pero sí, al menos, como una huella del paso de Dios por el tiempo ${ }^{18}$.

Antes que de ningún otro elemento, el ser personal existente que forma este bucle en el ser que es ya vivir a la manera de un humano, dispone de tiempo. No es exactamente que goce de tiempo ni que se alimente de tiempo ni que se represente tiempo: es que se distiende, se dia-croniza. Un tiempo no orientado a la muerte ni angustiado, pero sí, de alguna manera, pese a todo, orientado, atraído, investido. Tiempo que es la condición necesaria del alimento, del gozo, del deseo sin hambre del Bien, de la recepción de toda ternura, de la escucha de las palabras que suscitarán mis palabras, del ofrecimiento paradisiaco del mundo.

Ninguna reflexión nos transportará hasta el momento en que nació el tiempo y ninguna expectación podrá serlo del final absoluto del tiempo.

18 Si pudiera intentar desarrollar hasta el final esta sugerencia, obtendríamos un rasgo de la diferencia entre el judaísmo no cristiano y el cristiano; al menos daré algunos pasos en esta dirección enseguida. 
Estas zonas del misterio del tiempo señalan a otra aún más grave, metafísica y teológicamente decisiva: el tiempo es primordialmente $m i$ tiempo, no directamente el tiempo universal en que está el mundo y en el que insertamos la historia. Sin embargo, mi tiempo no tiene por qué ser sólo mío, cuando ya de entrada se me muestra como una alteración que está en la base inmemorial de toda otra alteración y de toda libertad, o sea, también del despliegue de todas mis potencias corporales, anímicas y espirituales.

El tiempo es así como la estela de la palabra que me dirige la autoridad en cuya iniciativa está hablarme. Es ya sentido orientado, sobre el que florecen todos los demás sentidos.

Claramente no es el tiempo mismo lo absoluto, pero sí pertenece a la transcendencia absoluta aquello o aquél que pronuncia sobre mí mi tiempo y que coordina en el seno del misterio los tiempos de todas nuestras existencias y de todas las cosas que las rodean y las sustentan y las entusiasman o las matan ${ }^{19}$.

¿Se puede dar algún paso todavía más acá y más al centro y al fondo de uno mismo? Posiblemente sólo por la vía indirecta de observar si cabe que se extinga el tiempo, o sea, que pierda todo sentido y toda orientación; o, lo que es lo mismo, que en vez de proporcionarnos la apertura de las restantes posibilidades para existir, venga a cerrarlas todas y se cierre él también sobre sí mismo en un círculo de puro vértigo. Seguir vivo pero hundido en la falta absoluta de sentido; no poder esperar ni siquiera la esperanza de que algo otra vez sea posible. Una detención, una suspensión, una abstención definitiva que ni siquiera logra ver que sea definitiva porque no remonta ni un ápice sobre sí misma. En la espiritualidad clásica se habló de acedia (que ya etimológicamente significa la no-ocupación con nada, el total dés-oeuvrement de algunas descripciones contemporáneas) ${ }^{20}$; Kierkegaard y Dostoievski la entienden como

19 Es de la máxima importancia cohonestar las descripciones del ser humano que muestran cómo el acontecimiento muerte lo despierta al misterio del ser y el bien, con éstas otras, propias sobre todo de la fenomenología de Levinas, que no incluyen la finitud en su panorama. De las primeras me he ocupado reiteradamente desde mi libro de 2006: Del dolor, la verdad y el bien.

20 Maurice Blanchot, Giorgio Agamben, Jean-Luc Nancy, en múltiples direcciones. Pero debe consultarse también la prodigiosa descripción de la duda radical en la obra culminante de Pável Florenski, La columna y fundamento de la verdad (1914), carta segunda. 
desesperación, infinita duda sin salida, enfermedad en la que se está a la muerte sin poder ni morir. Por momentos, los personajes a los que lleva su contradictoria visita el Dante en los círculos de los infiernos expresan en silencio esta consunción que, en el frío, ofrece su horrendo contraste al calor de la zarza del Señor. El joven Levinas, apoyado en la literatura asfixiada de Blanchot, acude a los recuerdos de las peores duermevelas, donde sólo hay, donde sólo hay el haber mismo, sin entes, sin nada.

Desde los márgenes de estas zahúrdas del diablo donde no se puede entrar — sólo caer- porque no se puede salir, tener tiempo se nos muestra como la dicha en el centro de la dicha, como la bendición y hasta la bondad en el corazón del maestro interior o, quizá, más bien, en las palabras primordiales que él, desde más arriba del tiempo, nos ha dirigido (y habló, y fue; $y$ habló y fui).

Ahora bien, esta excavación del tiempo en sus instantes, que ha sido parte esencial de la obra de los más grandes filósofos en nuestra época y que quizá anticiparon Sócrates y Platón en sus discursos sobre el alma, el amor y el bien perfecto, quedaría incompleta y sin rendir, desde luego, sus frutos si no consideramos el porvenir de nuestra existencia.

Se hace aquí precisa una cierta abreviatura, cuyo sentido puede anunciarse abruptamente: el origen del tiempo es divino si y sólo si la presencia del otro humano critica radicalmente mi libertad a la vez que la suscita de nuevo a cada momento. Y esto es lo mismo que decir que el origen del tiempo es divino si y sólo si la voluntad de herir al otro próximo es un mal de infinita perversidad - como si el otro próximo fuera la carne de Dios mismo—. Porque la aparición del otro empírico suscitará, resucitará, la memoria de lo absolutamente santo. En cambio, allí donde el otro no haga memoria del santo, es que la maldad y la necedad de los seres humanos acuciados por el miedo que sus hambres insaciadas les producen, han velado el Bien con el fantasma de algo Sagrado. Pero lo Sagrado en que confundirnos todos y en que desaparezca la individualidad, la responsabilidad personal, la bondad quebradiza de cada uno, aunque parezca ser la Vida impersonal, es realmente sólo la Muerte —esa manifestación engañosa de la Desesperación-.

La compañía de los otros seres humanos puede y debe, así, ser interpretada como la reclamación constante de la libertad en toda su belleza, o sea, en su bondad. De esta compañía vienen a nosotros el mundo y la historia, pero cada próximo humano, incluso el que sólo habla odio, es ya ahí delante el principio de la oración: su cuerpo, su alma, su espíritu 
me mandan categóricamente, si es que mis ojos se han ejercitado en la verdad y mis manos han dado ya, aunque sea con titubeos, algo a alguien reiteradamente.

El misterio de la coexistencialidad se revela inicio simultáneo de la filosofía primera y de la religión auténtica. Claro que no por ello deja de ser paradójica la encarnación de Dios en un judío galileo de hace dos mil años; pero cabe empezar a entender algo cuando la intersubjetividad muestra ser enseñanza, bondad, memoria Dei, ruptura de la totalidad, hundimiento de lo sagrado y futuro infinitamente abierto.

Sólo, ya se ve, la oración continua es oración; pero todos somos mucho más discípulos del Bien que buenos. Podríamos ser, sin embargo, aquel niño de Cafarnaúm.

\section{REFERENCIAS}

Chrétien, Jean-Louis. L'arche de la parole. París, 1998.

Chrétien, Jean-Louis. Lueur du secret. París, 1985.

Florenski, Pável . La columna y fundamento de la verdad. [1914]. Traducido por Francisco José López Sáez. Salamanca, 2010.

Heidegger, Martin. Sein und Zeit. Tübingen, 1927.

Henry, Michel. Phénoménologie matérielle. París, 1990.

Henry, Michel. Incarnation, une philosophie de la chair. París, 2000. Traducido por Javier Teira, Gorka Fernández, y Roberto Ranz. Salamanca, 2001.

Jaspers, Karl. Philosophie. Berlín, 1932.

Kant, Immanuel. Religionsphilosophie Pölitz 1817. Vol. 28. Vol 5 de la edición académica. Berlín, 1972. Traducido por Alejandro del Río y Enrique Romerales. Madrid, 2000.

Kierkegaard, Søren. El concepto de angustia. Traducido por Darío González y Óscar Parcero. Madrid, 2016.

Kierkegaard, Søren. Postscriptum no científico y definitivo a Migajas de filosofía. Traducido por Javier Teira, y Nekane Legarreta. Salamanca, 2011.

Klausner, Joseph. Yeshua ha-Nozrí. Jerusalén, 1922.

Klausner, Joseph. Jesus von Nazareth. (1930). 3. ${ }^{\text {a }}$ ed. Berlín, 2021.

Lacoste, Jean-Yves. "L'intuition sacrementelle". Revue théologique de Louvain 42 (2011): 496-525. 
Lacoste, Jean-Yves. Expérience et absolu. París, 1994. Traducido por Tania Checchi. Salamanca, 2010.

Levinas, Emmanuel. Totalidad e infinito. Traducido por Miguel GarcíaBaró. Salamanca, 2020.

Levinas, Emmanuel. De otro modo que ser o más allá de la esencia. Traducido por Jesús María Ayuso. Salamanca, 2021.

Maldiney, Henri. Penser l'homme et la folie. Ginebra, 2007.

Martín Velasco, Juan. Introducción a la fenomenología de la religión. Madrid, 2006.

Platón. Fedón.

Romano, Claude. L'événement et le monde. París, 1999. Traducido por Fernando Rampérez. Salamanca, 2012.

Rosenzweig, Franz. La estrella de la redención. [1921]. Traducido por Miguel García-Baró. Salamanca, 2021.

Schleiermacher, Friedrich Daniel. Discursos sobre la religión. Traducido por Arsenio Ginzo. Madrid, 1990. 